\title{
EM TEMPOS DE PANDEMIA, LUZ, CÂMERA E AÇÃO PARA A EDUCAÇÃO ONLINE: DO DISCURSO À PRÁTICA DESEJADA
}

Adriele da Silva Freitas Oliveira ${ }^{\mathrm{i}}$

Alessandra da Costa Abreu ${ }^{\text {ii }}$

Ana Paula da Silva Conceição Oliveira ${ }^{\text {iii }}$

Resumo: Este artigo apresenta reflexões sobre as propostas de educação remota que têm sido adotadas por escolas da rede pública e particular de ensino de modo a atender a exigência anual no cumprimento de 800 horas aulas estabelecida pela LDB 9394/96, também durante o período de pandemia da COVID-19 e quarentena decretada pelos chefes dos poderes executivos. Para isso, analisamos três diretrizes diferentes, seguidas por instituições de ensino nos âmbitos federal, estadual e municipal pertencentes ao Estado do Rio de Janeiro. Este debate se faz necessário na medida em que políticas de educação na perspectiva transmissiva de educação a distância, equivocadamente denominadas de online, estão sendo implantadas ignorando que a dificuldade no acesso a internet ainda é uma realidade brasileira.

Palavras-chave: Educação online; Covid-19; Isolamento físico.

\section{EN TIEMPOS DE PANDEMIA, LUZ, CÁMARA Y ACCIÓN PARA LA EDUCACIÓN EN LÍNEA: DEL DISCURSO A LA PRÁCTICA DESEADA}

Resumen: Este artículo presenta reflexiones sobre las propuestas de educación remota que han sido adoptadas por las escuelas públicas y privadas para cumplir con el requisito anual en el cumplimiento de 800 horas de clase establecidas por LDB 9394/96, también durante el período pandémico de COVID-19 y cuarentena decretados por los jefes de los poderes ejecutivos. Para esto, analizamos tres pautas diferentes, seguidas por instituciones educativas a nivel federal, estatal y municipal pertenecientes al Estado de Río de Janeiro. Este debate es necesario en la medida en que las políticas educativas en la perspectiva transmisiva de la educación a distancia, erróneamente llamada en línea, se están implementando ignorando que la dificultad para acceder a Internet sigue siendo una realidad brasileña.

Palabras- clave: Educación en línea; Covid-19; Aislamiento fisico.

\section{Já que educar é um ato político, clamamos por uma coerência necessária}

Como professor não devo poupar oportunidade para testemunhar aos alunos a segurança com que me comporto ao discutir um tema, ao analisar um fato, ao expor minha posição em face de uma decisão governamental (FREIRE, 1996 p. 135).

Ao percorrer o campo da educação como professoras pesquisadoras, temos percebido o quanto o saudoso Paulo Freire nos compõe como pessoas e profissionais movidas por uma curiosidade inquietante que nos faz desejar aprender cada vez mais com nossos pares, através de relações sempre dialógicas (FREIRE, 1996). As conversas, de essência rizomática e indirigível, são capazes de nos levar a lugares imprevisíveis (SERPA, 2010), fundamentais às relações humanas e às pesquisas. Até mesmo aqueles que falam com entonação ofensiva, na tentativa de fazer prevalecer sua voz em detrimento da voz outro, de 
algum modo, têm contribuído para pensarmos em novas estratégias de enfrentamento a esses mesmos discursos ofensivos.

Numa inspiração freiriana, resistir tem sido a prática por nós pensada para prosseguir numa docência que também é discência, compreendendo e legitimando a educação como ato político. Com Freire aprendemos que nas relações estabelecidas com os outros que diferem de nós em muitos aspectos, especialmente no nível da política, é que a coerência entre o que fazemos e o que dizemos, permite a possibilidade do encontro. Em tempos tão sombrios, assumimos a ideologia da ética e do respeito ao próximo, buscando responder através da pesquisa aquilo que o desgoverno tem respondido de forma autoritária e insana, inclusive numa época de pandemia.

Nesta escrita delimitamos algumas reflexões sobre as realidades de nossos campos de trabalho e pesquisa, entre eles, destacamos ações e posicionamentos de três esferas educacionais, sendo elas instituições de ensino no âmbito federal, estadual e municipal, ambas pertencentes ao Estado do Rio de Janeiro. Falamos sobre três dos tantos lugares atravessados pela pandemia do Coronavírus, na qual uma quarentena instaurada, sob o discurso do medo, provocou à sociedade processos de reinvenção, readaptação e dribles extremamente necessários. Assim como Boaventura Santos (2020), concordamos que qualquer quarentena é discriminatória, trazendo mais dificuldades para uns do que para outros, neste sentido não há como negar que estudantes da escola pública, pertençam ao grupo dos que também padecem de "uma especial vulnerabilidade que precede a quarentena e se agrava com ela" (SANTOS, 2020, p. 15).

Como estratégia metodológica, junto a análise documental, os referenciais teóricos aqui apresentados nos ajudaram na construção de uma pesquisa qualitativa que propusesse refletir sobre o momento atual quando uma suposta educação online surge no período pandêmico, gerando tensões entre o discurso e a prática desejada. Nesta sintonia contamos com as contribuições de Santos (2014), Silva (2014), Santos (2020) e Freire (1996), entre outros autores citados ao longo do texto na fundamentação de nossa escrita. Observamos que o desafio da reinvenção nos coloca em alerta nesse momento em que os encontros presenciais se tornam impossíveis, porém também concordamos que a educação online é uma modalidade de ensino importante, com especificidades metodológicas que não se encaixam aos discursos esvaziados, insistentes em manter processos de ensinagens sem que as realidades sociais sejam visibilizadas.

Ressaltamos que anterior à política de distanciamento social, nossas pesquisas já caminhavam em busca de uma educação online comprometida, ética e responsável. Dialogávamos sobre a potência da cibercultura onde o rompimento com o tempo e o espaço possibilitava outros modos de pensar e fazer a educação em nossos âmbitos de atuação, sendo estes instituições de ensino federal, estadual e municipal. 


\section{Quando não fazer educação a distância significa um ato de resistência}

Vivemos um momento excepcional na história mundial, atividades dos diversos setores da sociedade encontram-se suspensas ou tendo o ambiente laboral transferido para a própria casa. Se no mundo contemporâneo, com os diversos artefatos digitais e em rede, os limites entre o trabalho e os momentos de descanso já se encontravam turvos, nessa nova configuração de vida que nos encontramos e somos obrigados a viver, eles por vezes se tornam inexistentes.

Entre as restrições de trânsito por conta de uma pandemia provocada por um vírus com nível de proliferação e contaminação altas, as instituições de ensino e seus estudantes ao redor do mundo foram extremamente afetados. A UNESCO vem acompanhando e contabilizando em seu site a influência que a COVID-19 vem causando na vida de crianças e jovens. Até o dia 10 de junho de $2020^{\mathrm{iv}}$, em sua página, a entidade apresentava que 63,3\% das instituições escolares se encontravam fechadas no mundo, resultando em um pouco mais que um bilhão de estudantes sem frequentar a escola.

Com a suspensão das atividades presenciais nas escolas, iniciativas de implementação do ensino a distância vem ganhando força no Brasil, tanto na rede privada quanto na rede pública de ensino. Transmissões ao vivo, as chamadas lives, caíram no gosto popular desde que a política de isolamento físico (HENRIQUE, 2020) foi implementada no país. Na rede pública municipal do Rio de Janeiro, um aplicativo de celular foi lançado, segundo uma nota no site da própria prefeitura ${ }^{\mathrm{v}}$, com o objetivo de que os alunos continuem estudando durante o período de suspensão das aulas. A nota também relata que os professores continuam "repassando conteúdos e atividades por meio das redes sociais da secretaria". Esse aplicativo busca atender todos os segmentos oferecidos pela rede, desde Educação Infantil aos Jovens e Adultos. Na rede pública estadual de ensino a iniciativa inicial anunciada seria a distribuição de chips de telefonia com acesso a internet para alunos e professores, porém esse planejamento não se materializou. Alguns alunos receberam material impresso e as aulas seguem sendo ministradas em um ambiente virtual online, mesmo que nem todos tenham acesso.

No Estado do Rio de Janeiro, o Colégio Pedro II, uma instituição de Educação básica da rede federal, também teve suas atividades de ensino suspensas. A referida instituição atende desde crianças da Educação Infantil, a partir dos três anos de idade até jovens no Ensino Médio. Como instituto federal, também são oferecidos cursos de pós-graduação e, no ano de 2020 teve as primeiras turmas de licenciatura formadas. Essa descrição é apenas um mínimo fragmento do universo plural aos quais crianças, jovens e adultos formam e que tiveram seus cotidianos afetados pelos efeitos da pandemia viral. Nesse fragmento, diferentes realidades convergem tanto no que diz respeito a especificidades de faixa etária, condições socioeconômicas, configurações familiares e até mesmo culturais. Esses são apenas 
alguns exemplos da diversidade de variáveis que esperamos que sejam consideradas ao pensar, analisar, propor e implementar alternativas a impossibilidade de frequência às escolas.

Após a suspensão das aulas, essa instituição se posicionou contrária a Educação a distância em nota divulgada a comunidade escolar no dia 18 de março. Entre os motivos que justificavam tal posicionamento a escola pontua o não acesso de todos os estudantes a computadores e rede de internet; o não desenvolvimento nos estudantes de uma cultura prévia de acesso ao ambiente virtual de aprendizagem; a falta de preparo, infraestrutura e planejamento do corpo docente; e o não amparo legal para a substituição das aulas presenciais pelas aulas à distância na Educação Básica, principalmente na Educação Infantil e nos anos iniciais do ensino fundamental ${ }^{\mathrm{vi}}$.

Segundo o quarto parágrafo do artigo 32 da Lei de diretrizes e bases da Educação Nacional (LDBEN), "O ensino fundamental será presencial, sendo o ensino a distância utilizado como complementação da aprendizagem ou em situações emergenciais" (BRASIL, 1996, s/p). Essa modalidade de ensino não é regulamentada no que tange a Educação Infantil e em um universo diverso de atendimento dessa escola, oferecer o ensino para determinados segmentos e, mesmo nesses segmentos respaldados pela lei, tal atitude seria de exclusão daqueles que não possuem o acesso, conforme pontuado pela própria escola em seu comunicado. Essa exclusão também contraria os princípios I (um) e XIII (treze) defendidos pela lei 9394/96 (LDBEN), na qual estabelecem respectivamente igualdade de condições para o acesso e permanência na escola e garantia do direito à educação e à aprendizagem ao longo da vida.

A problemática se torna ainda mais complexa quando se fala especificamente da Educação Infantil. Durante anos, esse segmento vem se consolidando a base de lutas pelos direitos das crianças e infâncias. Apesar de a Constituição Federal definir como obrigação do Estado e direito da criança o acesso a Educação, apenas em 2013 ficou estabelecido a obrigatoriedade de matrícula a partir dos quatro anos de idade na escola, integrando a Educação infantil a Educação Básica e tornando-a também uma etapa obrigatória na escolaridade da criança.

Diferentemente das etapas de ensino posteriores na Educação básica, a Educação Infantil não se configura como preparatória, sendo descrita como sua finalidade no artigo 29 da lei 9394/96 "o desenvolvimento integral da criança de até 5 (cinco) anos, em seus aspectos físico, psicológico, intelectual e social, complementando a ação da família e da comunidade” (BRASIL, 1996, s/p).

Segundo as Diretrizes Curriculares Nacionais (BRASIL, 2013, p. 85), a Educação Infantil é orientada por planos de ações das instituições materializados em propostas pedagógicas ou projetos pedagógicos, estes definem metas a serem alcançadas de desenvolvimento, cuidados e aprendizagens pretendidas. 
Na sua execução, a instituição de Educação Infantil organiza seu currículo, que pode ser entendido como as práticas educacionais organizadas em torno do conhecimento e em meio às relações sociais que se travam nos espaços institucionais, e que afetam a construção das identidades das crianças (BRASIL, 2013, p. 85).

As vivências no espaço escolar constituintes da Educação Infantil perpassam desde as relações sociais a construção das identidades das crianças. As experiências cotidianas são intencionalmente planejadas e avaliadas considerando o desenvolvimento e as potencialidades de cada criança. O documento define também a criança como sujeito histórico e de direitos, sendo assim, esta ocupa o lugar central no planejamento pedagógico, desenvolvendo ações, relações e práticas cotidianas com diferentes pessoas em diferentes idades. "Nessas condições ela faz amizades, brinca com água ou terra, faz de conta, deseja, aprende, observa, conversa, experimenta, questiona, constrói sentidos sobre o mundo e suas identidades pessoal e coletiva, produzindo cultura" (BRASIL, 2013, p.86). Brincar, conversar, questionar e construir sentidos pressupõe a existência e presença do outro, essas vivências e interações não acontecem apenas com professores e adultos, mas também e principalmente com outras crianças em ambientes propositalmente pensados e organizados, garantindo mediações de qualidade.

Com base nos documentos oficiais, o grupo de professores atuantes na Educação Infantil do Colégio Pedro II também manifestou posicionamento contrário ao Ensino a distância nesse segmento em uma nota explicativa a sociedade, famílias e responsáveis pelas crianças. No texto, o grupo de professores explica sobre as especificidades do segmento e os respaldos legais. Explica também que a proposta adotada pela escola é compreendê-la como um espaço de interação, tendo a escuta e o cuidado como princípios fundamentais na proposta pedagógica.

A Educação Infantil, em nossa escola, privilegia os vínculos, o afeto, a escuta e o cuidado, o que não pode ser ofertado por atividades remotas, descontextualizadas do nosso cotidiano, e, portanto, vazias de sentido pedagógico. O planejamento das atividades pedagógicas ocorre de modo alinhado aos interesses e desejos do grupo de crianças e adultos. Por essa razão a nossa proposta jamais caberia nos moldes de um espaço virtual, no qual não existe uma estante para buscar o pote de massinha, um pátio para correr, uma árvore para regar, um brinquedão para encontrar com os colegas de outras turmas, entre tantas outras vivências valiosas e imprescindíveis que instigam a criatividade, a observação, provocam questionamentos e investigações. ${ }^{\text {vii }}$

A nota, publicada no dia 24 de abril de 2020, deixa evidente que os princípios do afeto, do cuidado, da escuta e dos vínculos permitem a construção de um currículo integrado com as experiências do cotidiano, pautado na e pela infância e não em uma lista de conteúdos.

Como forma de manter os vínculos criados entre a escola e as crianças na volta às aulas em março e construído entre os grupos já formados nos anos anteriores, a equipe atuante na Educação Infantil produz e disponibiliza em um blog institucional, pelo menos uma vez na semana, um texto informativo sobre alguma temática pertinente ao contexto ou às famílias, sugestão de atitudes e vivências em 
conjunto, vídeos de animações criados relembrando produções e projetos desenvolvidos nos anos anteriores pelas turmas e, até produções audiovisuais remotas desenvolvidas com as próprias crianças a fim de fortalecer o protagonismo destas. É importante ressaltar que todas as ações propostas não se caracterizam como Educação a distância, uma vez que os textos introdutórios sempre elucidam sobre a intencionalidade da presença e não da promoção de aprendizagens.

Em um manifesto escrito e publicado no dia 20 de abril de 2020 pela Associação Nacional de Pesquisa em Pós-graduação em Educação (ANPEd) ${ }^{\text {viii }}$, a entidade se posiciona contrária à oferta da Educação a distância e pretende alertar profissionais da Educação Infantil quanto a inadequação dessa proposta no segmento. A Associação discorre sobre a seriedade do momento e a necessidade de um planejamento governamental (em regime de colaboração federativa) e intragovernamental (diferentes setores de políticas públicas), porém a União deixa a cargo apenas dos estados e municípios a responsabilidade de planejar ações desarticuladas e pontuais, conforme pontuamos ao longo desse texto. O manifesto também expressa preocupação com as condições que as crianças estão vivendo, se suas famílias possuem renda, se vivem em situação de risco, alimentar, acesso a saúde, interrupção de eventuais atendimentos educacionais especializados, entre outras situações mais preocupantes que a paralisação ou uma eventual perda do ano letivo. O que deveria ser considerado é a sobrevivência das pessoas, principalmente o público e sua condição de vida que compõe majoritariamente as redes públicas e as instituições privadas que atendem esse grupo.

Outro ponto a ser considerado é a necessidade que algumas famílias tiveram de se reorganizar frente a demandas do lar, trabalho e cuidados das crianças. As casas passaram a acomodar diferentes funções, mas para as crianças ela é apenas o lar.

\section{Entre a cibercultura, imperam invisibilidades e tecnologias de reação}

Anterior a atual pandemia, o cenário formativo dos estudantes e professores, permeado por tecnologias digitais já compunha os nossos estudos na educação básica. Entre as pesquisas realizadas, o Curso Normal oferecido pela rede estadual do Rio de Janeiro, encontra-se como um dos campos investigados, na tentativa de conhecermos suas práticas tecnológicas, redes de convivência online e sentidos produzidos no cenário da cibercultura. Notamos que as práticas culturais permeadas pelas tecnologias digitais apresentam-se na arquitetura social, nos fazendo pensar estas tecnologias como uma espécie de extensão que institui um novo equilíbrio entre todos os sentidos e faculdades humanas (MCLUHAN, 2007), gerando novas atitudes, modos de perceber e agir no mundo, inclusive no campo educacional. 
Concomitante ao cenário da cibercultura, entendida como a cultura fundamentada na internet, nos artefatos eletrônicos e nas tecnologias da informação e comunicação, também há o terreno das desigualdades sociais, da exclusão e da invisibilidade. Nesta esfera, temos caminhado em busca de outras tecnologias compreendidas como tecnologias de reação (OLIVEIRA, 2019), àquelas desenvolvidas por professores e alunos em seu cotidiano educacional que rompem com os modos globalizados de consumo. Em relação às tecnologias que demarcam os ideais da globalização e seus fetiches, as compreendemos como tecnologias de controle (SIBILIA, 2012), presentes nas políticas educacionais e nos currículos, agora mais do que nunca.

$\mathrm{Na}$ sociedade capitalista, a educação assume hegemonicamente a incumbência de garantir a transmissão de conhecimentos e valores necessários para a "legitimação da relação antagônica entre capital e trabalho" (SOBZINSKI; DIOGO; MASSON, 2015, p. 1213). Não há como negar os (des) caminhos traçados pela lógica neoliberal descabida, insistente em transferir para a educação a lógica de mercado, por meio da venda de cursos e materiais didáticos, de tecnologias e programas formativos e avaliativos (HYPOLITO, 2019) que violentam a autonomia das instituições públicas de ensino e caminham numa proposta de massificação da educação a distância.

Primeiramente é fundamental destacar o potencial das tecnologias digitais em educação sem que isso signifique uma deturpação de seu uso, não estamos falando sobre instrumentalizar o trabalho dos professores ou capacitá-los para a transmissão de conhecimento aos seus alunos. As tecnologias móveis já estavam na escola, nas mãos dos estudantes e também dos docentes na modalidade de ensino presencial, talvez fosse necessário apenas perceber o ganho das experiências formativas digitais quando seus praticantes através de muita criatividade driblavam as sociologias das ausências (SANTOS, 2002) transformando-as em políticas de presença (OLIVEIRA, 2017).

Ao discutir a reinvenção da emancipação social, Santos (2002) reflete sobre alternativas referentes à globalização neoliberal e ao capitalismo global, criadas pelos movimentos sociais que têm lutado contra atos de exclusão e invisibilidade. Nesta perspectiva "o objetivo da sociologia das ausências é transformar objectos impossíveis em possíveis e com base neles transformar as ausências em presenças" (SANTOS, 2002, p. 12). Estaríamos diante de uma globalização contra hegemônica traduzida pelas iniciativas e experiências perspicazes dos grupos e movimentos sociais que, a partir de suas realidades e práticas, buscam romper com a hegemonia criada pela globalização neoliberal.

As experiências e iniciativas contra hegemônicas, denominadas por Oliveira (2017) de políticas de presença estão sendo legitimadas por muitos professores e estudantes no cenário pandêmico atual que, apesar dos inúmeros problemas enfrentados nas suas experiências de educação online, reagem às tormentas sociais se posicionando eticamente a esse respeito. Temos visto resistências necessárias especialmente quando práticas de educação a distância improvisadas são impostas sem que as 
vulnerabilidades sociais sejam consideradas ou mesmo quando as conduções e dinâmicas do trabalho educacional não estão voltadas para os conteúdos programáticos, mas para a sociabilidade e a afetividade que nos permitem sentir mais próximos do que distantes.

É importante frisar que experiências formativas mediadas pelas tecnologias digitais já eram praticadas por muitos professores e estudantes da rede pública de ensino antes mesmo da quarentena. Já havia passos em sintonia com a proposta da educação online, que diverge totalmente de "uma mera evolução das práticas massivas da EaD” (SANTOS, 2014, p. 18). Em acordo com a autora, a educação online afina-se aos atos de currículo potentes, demarcados por práticas comunicacionais, interativas e hipertextuais na cibercultura. Enquanto elemento potencial tanto para a educação presencial quanto para a educação a distância, a educação online possui especificidades que trazem ao processo educacional a possibilidade de interação e convivência mais promissora. Nesta perspectiva, distancia-se totalmente da proposta de educação bancária (FREIRE, 1996), assim como das práticas de transposição do ensino presencial para o ambiente virtual, exigindo um pensar sobre. Este momento configura-se como emergencial, carecendo de problematizações a respeito das ensinagens em ambientes virtuais que não se esgotam no ensino superior, mas se estendem às escolas de Educação Infantil, Ensino Fundamental e Médio.

Apesar de inúmeras práticas formativas já caminharem em defesa do conceito de educação online, muito ainda há de avançar, especialmente no que se refere às políticas de acesso à internet, de formação docente para o uso das tecnologias digitais em educação assim como sobre o que se pensa a respeito de tecnologia no campo educacional; comumente presente nas políticas educacionais numa perspectiva instrumental (OLIVEIRA, 2019). Tal afirmativa se confirma quando nota-se uma ideologia oficial, presente nas políticas em texto, caminhando em defesa das demandas da sociedade globalizada. Neste panorama, a tecnologia estaria se referindo a uma importante ferramenta para a formação de mão de obra qualificada, ou pedagogização do ensino, onde "as práticas sociais e as relações comerciais estão cada vez mais dependentes das mídias e das tecnologias da informação e comunicação (TIC)" (SEEDUC, 2013). Sob esta égide têm caminhado as políticas educacionais, afirmando ser imprescindível que o professor esteja adaptado a este novo padrão como resposta a uma realidade que já faz parte do cotidiano dos estudantes e do mercado de trabalho.

A educação online é uma modalidade de ensino importante, com características muito específicas, que através da possibilidade de unir mídias em ambientes virtuais de aprendizagem trazem consigo metodologias diferenciadas, fundamentadas na comunicação bidirecional (SILVA, 2014), onde professores e alunos têm a possibilidade de partilhar conhecimentos, aprendizagens, produzir conteúdos de forma colaborativa, conviver e estabelecer relações dinâmicas e interativas. Já experienciávamos este conceito em nossas práticas como professoras da educação básica em nossas realidades institucionais. 
Mesmo nesta esfera epistemológica, também sofríamos as barreiras da infraestrutura, a falta de conexão à internet com qualidade, a ausência de recursos audiovisuais e de acesso aos computadores, normalmente sucateados, trancados em alguma sala ou subutilizados. Muitos eram e continuam sendo os enfrentamentos cotidianos não só nossos, mas de outros colegas nas inúmeras escolas de educação básica, inclusive nas instituições estaduais do Rio de Janeiro que oferecem o Curso Normal.

Convém ressaltar que a tecnologia digital deveria ser uma entre tantas outras janelas abertas ao conhecimento e não instrumento de controle, vigilância e transposição de conteúdos programáticos. Em meio às problemáticas de falta de infraestrutura encontradas, movimentos de resistência já se mostravam fecundos quando os celulares dos estudantes eram acessados na sala de aula para sanar uma dúvida coletiva, para a leitura de um texto em tela, para registrar imagens e áudios importantes ou mesmo interagir nos ambientes virtuais de aprendizagem por nós criados através do Facebook e Whatsapp nossa plataforma oficiosa ${ }^{\mathrm{ix}}$. Nestes espaços já construíamos ações contra hegemônicas, fortalecendo nossas práticas políticas e também poéticas, em contraposição a subutilização das tecnologias digitais, da cibercultura e de consumos irreflexivos.

O limite que encontrávamos esbarrava-se na ausência de banda larga e redes de wifi, na qualidade de ponta dos aparelhos, tablets, notebooks ou computadores, utilizando apenas o que tínhamos em mãos, nossos celulares com conexões de planos pré-pagos que parte dos alunos possuía ou o que as professoras muitas vezes dispunham. Os que não tinham redes wifi em suas residências consumiam as disponíveis nos lugares que ambos freqüentavam fora da escola, pelo bairro, vizinhança ou outros espaços comerciais e sociais. Diante da realidade imposta, íamos construindo táticas "vigiando para captar no voo possibilidades de ganho" (CERTEAU, 2014 p. 46), encontrando nos não lugares as circunstâncias favoráveis que nos ajudassem a tornar os acontecimentos em ocasiões propícias para nossas práticas cotidianas online, modos de fazer onde legitimávamos as políticas de presença.

Na plataforma oficiosa, compartilhávamos discussões, trocávamos ideias, artes, leituras, vídeos, eventos e afins. Não era um ambiente virtual de aprendizagem onde elaborávamos enunciados e aguardávamos as respostas dos alunos, como uma espécie de exercícios de fixação, afinal nossa compreensão a respeito do que seja enunciar distancia-se muito das perguntas e respostas padrão, oriundas da concepção de aula como um encontro ritual, de transmissão de conhecimento (GERALDI, 2010) que muitos de nós fomos e ainda somos educados. Em relação ao conceito de enunciado, concordamos que "enunciando, estamos agindo sobre o Outro, argumentando" (GOULART, 2007, p. 96), o que se distancia completamente da elaboração de perguntas e respostas automatizadas, compreendidas como certas ou erradas.

Atualmente, no cenário pandêmico do Coronavírus, as escolas estaduais foram submetidas à necessidade de fazer o ensino a distância $(\mathrm{EaD})$, não era uma alternativa, mas uma exigência da secretaria 
de estado de educação do Rio de Janeiro, frente à situação instaurada. Com isso vivenciamos tamanha problemática não só de reconfiguração do ensino, mas de adaptação ao "novo normal” x, no qual professores e estudantes isolados do convívio físico precisaram organizar suas rotinas para aprender e ensinar a distância. De repente, professores e alunos receberam a incumbência de acessar a plataforma de ensino virtual, o Google Classroom, onde teríamos um acesso irrestrito com inúmeras ferramentas disponíveis de forma ilimitada. Contas e cadastros foram criados, cursos rápidos na versão virtual foram oferecidos para os docentes conhecerem a plataforma e suas ferramentas e iniciarem imediatamente os trabalhos. Tínhamos agora a oportunidade de fazer a educação a distância? E quais são as realidades de nossos professores e alunos? E os problemas de conexão, as novas rotinas em casa devido ao isolamento físico, quais seriam nossas demandas reais?

Vivenciamos a problemática não só de aprender o manuseio dos recursos técnicos, devido à disponibilização de ferramentas novas para muitos educadores e estudantes, como também as questões metodológicas e de acessibilidade, especialmente em relação aos discentes, em sua maioria com dificuldades de conexão à internet. Muitos professores aumentaram seus pacotes de dados devido às demandas das aulas, pois além da carga horária que tinham no Estado também cumpriam suas regências virtualmente em outras instituições, inclusive em tempo real.

$\mathrm{O}$ calcanhar de Aquiles na vida de muitos professores referiu-se à metodologia de ensino na modalidade a distância. Num passe de mágica, docentes precisaram adaptar-se a uma educação denominada de online, mesmo sem formação específica na área. Os resultados não demorariam a chegar, todos foram invadidos pelo receio da evasão escolar e do distanciamento dos alunos, entre insistências e resistências era preciso acessar a plataforma, preparar atividades e "abastecer" os alunos com tarefas. Os grupos de Whatsapp ganharam mais vida, pois entre recomendações, orientações e trocas de ideias a necessidade de fazer $\mathrm{EaD}$ era latente. $\mathrm{Na}$ busca pelas táticas, percebemos que trabalhos e projetos foram integrados entre professores de inúmeras disciplinas, nas quais aqueles que já possuíam experiência com as tecnologias digitais e com a educação online se solidarizaram com os que pouco ou nada sabiam a esse respeito.

Os celulares têm tocado em uma freqüência frenética, embalados aos diferentes sons dos grupos escolares, a festa tecnológica entre o trágico e a crítica da cultura informacional (DUNLEY, 2005) se fez presente. Cada toque configurava o recebimento de tutoriais, vídeos e ou sugestões de atividades que poderiam ser realizadas na suposta educação online com os educandos. Neste cenário "festivo", realizávamos conversas, compartilhávamos ideias, explicações, anseios e receios; também inauguramos nossa pista de dança virtual configurando-a como um plantão tira dúvidas sobre o novo cenário educacional na tentativa de iluminar o que para muitos ainda era obscuro. Os encontros docentes 
realizados no Google Meet ${ }^{x i}$ foram marcados pela partilha de angústias, medos, dúvidas, orientações e saberes relacionados à pedagogia necessária na pandemia, afinal depois da festa também há a ressaca.

Entre as barreiras do novo instaurado permeado por tecnologias digitais e virtualidades, não tememos os potenciais da cibercultura, mas às estratégias neoliberais transferidas para a educação. É preciso estar atento aos modos tecnológicos globalizados de produção (GERALDI, 2010), pois estes tendem a ampliar a vigilância e controle sobre a educação pública, enaltecendo a desconstrução do Estado e o fortalecimento dos mercados (COUTO, 2020). Com isso somos vítimas das negociatas, vivendo o plano de fundo do capital, acessando uma plataforma virtual e trabalhando nela sob a titulação de melhor plataforma educacional, produzindo materiais, nossas artes de educar, autorias e inventividades de forma gratuita e generosa, afinal professores sabem fazer política e economia solidária. Na pandemia do medo, é preciso estar atento às manobras neoliberais, pois muitos são "os fatores de desumanização que estão inscritos nos modelos de fazer economia e política" (COUTO, 2020, p. 02).

Insistimos na pandemia do medo buscando refletir sobre o peso coletivo que este carrega sobre a sociedade, inclusive como uma das estratégias mais marcantes do neoliberalismo, medo este que sustenta a longevidade de suas políticas e ações em prol do enriquecimento próprio. Como Couto (2020) alerta, o medo fundamenta a escolha de ações messiânicas e neste sentido os "salvadores do mundo" não só adoram o medo como também fazem da gestão eterna de crises o seu alimento. Entre as artimanhas dos ditos salvadores, àqueles que já viviam em quarentena antes mesmo deste contexto pandêmico que atualmente nos assola, continuam vivendo às margens, sofrendo a invisibilidade. Conforme Santos (2020) ressalta, os moradores das periferias já sofriam outras emergências antes mesmo da atual emergência sanitária, sobre este aspecto convém afirmar que possuir acesso à internet neste panorama é uma entre tantas outras ausências reais para os que se encontram nos grupos dos invisíveis.

Entre as conversas on line, realizadas com os estudantes do Curso Normal, suas angústias referiam-se à problemática da conexão, a falta de recursos tecnológicos e ao atolamento de tarefas exigidas pelos educadores. A educação que de repente virou a distância foi acometida pela exigência de inúmeros exercícios, tarefas e conteúdos em função dos programas disciplinares. Este é o momento de transformar o vivido em perguntas, de aprender a aprender e não o já sabido ou definido (GERALDI, 2010), é tempo de romper com os conteúdos engavetados e com os modos tecnológicos globalizados de produção como aqui já foi dito.

Retomando as reflexões de Boaventura, grande parte da população do mundo não está em condições de seguir as orientações da Organização Mundial da Saúde (OMS) por viverem em situações de alta precariedade, onde todos os cômodos da casa resumem-se a um pequeno metro quadrado impedindo inclusive o distanciamento seguro. Falamos sobre a falta de sabão para higienizar as mãos, de alimentação saudável que possibilite uma boa imunidade para resistir ao vírus, de água potável e 
condições mínimas para a sobrevivência. Com dada realidade, a ausência de internet é um dos inúmeros outros problemas enfrentados pelos alunos, onde o discurso capital mais uma vez apresenta-se sedutor, porém distante do alcance de todos. De acordo com Bakhtin (1992), a fala sempre esteve associada às estruturas sociais, o que permite compreender que enquanto arena, a palavra confronta os valores sociais contraditórios. De um lado temos o discurso da classe dominante reforçando o seu poder e de outro as fugas e resistências dos que não admitem ser dominados; seriam os invisíveis reagindo e conquistando notoriedade, inventando suas tecnologias reativas.

Obviamente as tecnologias digitais tornam-se fundamentais antes, durante e depois da pandemia, devido às inúmeras possibilidades educacionais potencializadas pela cibercultura. Entre as boas iniciativas docentes e a intenção de acertar em um universo que para muitos deles é novo, esbarramo-nos com a problemática de conexão que é unânime na vida dos alunos, mas também presente nas realidades de vários educadores. Não cabe sustentar um discurso sobre tecnologias em educação se estas continuam inacessíveis, existem casas nas quais não há computadores e quando há, são compartilhados com toda a família, tornando-se a ferramenta de trabalho de ambos. Muitos alunos afirmaram necessitar usar os celulares dos responsáveis para realizar as tarefas e postá-las, devido à falta de um pacote de conexão suficiente para a demanda atual.

Entre expectativas e realidades, muito ainda há de ser feito, pois o quesito realidade tem sido árduo. Os normalistas têm questionado o quantitativo enorme de vídeos, imagens, áudios, arquivos de texto entre tantos outros que os mesmos precisam submeter na plataforma digital para atender às demandas conteudistas que lhe foram impostas nas inúmeras disciplinas que compõem a grade curricular de sua formação. Diante da falta e ou baixa qualidade de conexão, o plano de dados extingue antes mesmo de acessar todas as atividades transmitidas. Muitos alunos estão se sentindo desmotivados, entristecidos, cansados e angustiados com a desigualdade de acesso à educação. Os chips de conexão à internet que chegariam às residências dos alunos das escolas estaduais ficaram no âmbito teórico e não prático, os materiais impressos enviados, entendidos como material complementar trouxe um ensino dualista, confundindo ainda mais o corpo discente e também docente.

Os alunos que estavam conseguindo acessar a plataforma também fariam as atividades do material impresso e aqueles impossibilitados de acesso à internet cumpririam as atividades impressas recebidas, ficando para um momento posterior o complemento de carga horária através de aulas presenciais possivelmente aos sábados. Algo que ainda aflige a comunidade escolar, devido às muitas incertezas ainda existentes e em pauta de discussão.

É importante problematizar a realidade que está posta, chamando a atenção para a ampliação da desigualdade de acesso à educação na mesma escola, pois no ensino presencial os materiais eram disponibilizados e acessados por todos os alunos da turma, atualmente na modalidade a distância 
repentina, o cenário não é o mesmo. Vivemos desigualdades de acesso dentro e fora da escola pública, notando inclusive que instituições privadas de grande porte estão conseguindo suprir suas demandas pedagógicas com recursos tecnológicos por eles denominados de ponta, ressaltando uma altivez através do discurso de educação de qualidade com a técnica de sedução dos cantos de uma sereia.

Contudo, convém clarificar que os professores têm se disposto à reflexão, esforçando-se incansavelmente na busca pela reinvenção de suas práticas educacionais, diante da cruel pedagogia do vírus (SANTOS, 2020), resistindo e encarando as inseguranças e o medo conjuntural, reflexo das estratégias capitalísticas. Vivemos um misto de incertezas sobre um ano letivo parcialmente ou integralmente perdido, dependendo dos sentidos dados por cada um de nós em relação ao que é de fato educação. Quais são as relações construídas com nossos estudantes? O que eles têm nos dito sobre o atual momento? O que pensam a respeito de uma quarentena permanente que assola a vida de muitos grupos sociais, inclusive as suas, quando uma educação online é propagada sem que anterior a ela exista acesso à internet e as tecnologias digitais com qualidade, assim como conhecimentos teóricos e metodológicos que façam jus ao que realmente significa esta modalidade de ensino.

O posicionamento das redes municipais não tem sido muito diferente, em conversa on line com professores das redes municipais de São Gonçalo e Niterói/RJ, através do diálogo via Whatsapp constatamos que as aulas online também têm sido uma exigência. O posicionamento das secretarias de educação é que as escolas selecionem a plataforma que será utilizada, entendendo esta escolha como um processo autônomo. Como muitos professores não possuem formação para ministrar o oferecimento do ensino a distância, os dispositivos utilizados para a mediação online entre professores e estudantes referem-se aos que não exigem conhecimentos técnicos mais elaborados e que permitem mediações rápidas. Algumas escolas optaram que as aulas fossem transmitidas via WhatsApp, outras pelo Facebook e pela plataforma gratuita disponibilizada pelo Google Class ${ }^{x i i}$. No entanto, ambos os espaços dependem que docentes e discentes tenham internet de qualidade, o que na maioria das vezes não acontece.

Entre tantas outras questões os professores têm indagado sobre como estabelecer o contato virtual com os educandos que não possuem acesso à internet, especialmente por concordarem que "ensinar não é transferir conhecimento" (FREIRE, 1996, p. 47). Tais políticas servem para afirmar a desigualdade social, pois "ensinar exige apreensão da realidade" (FREIRE, 1996, p. 68). A afirmação de políticas educacionais no viés que ignora a situação econômica de uma grande parcela da população, só expande ainda mais os processos de exclusão. Muitos vivem à margem, violentadas por um sistema político cada vez mais opressor que ignora a necessidade de conexão para todos. Entre tantas conexões necessárias, o acesso à internet ainda é uma utopia. O Exame Nacional do Ensino Médio (Enem), por exemplo, que ao ter sido marcado durante este período pandêmico, precisou de muita pressão popular para garantir o seu adiamento $^{\text {xiii }}$. 
Além da dificuldade do acesso à internet, reafirmamos a problemática coletiva em relação às situações enfrentadas por muitas famílias no cumprimento das medidas de isolamento nos bairros economicamente precarizados. Falamos sobre espaços onde a falta de água é constante na rotina das famílias, dificultando a garantia de uma higiene eficaz no combate à doença. O Estado ao invés de adotar medidas de amparo às famílias mais pobres continua com políticas de invasão e enfrentamento nas comunidades. Não há como deixar de lembrar o ato de violência ocorrido no dia 18 de maio de $2020^{\text {xiv }}$, onde tiros de fuzil invadiram a casa do estudante João Pedro Mattos, mais um jovem negro de apenas 14 anos assassinado dentro de casa. Outra das tantas operações policiais terminadas em tragédia. João estava cumprindo o isolamento físico, conforme as normas da OMS, buscando preservar sua vida, mas a perdeu através do vírus de mais uma tecnologia de controle, vigilância e arbitrariedade. Uma violência interminável. Romper com as diferentes formas de exclusão que atingem cotidianamente jovens pobres de todo o país tem sido uma luta diária, cada vez mais reafirmada em tempos de pandemia.

Este é o momento de pensarmos em outros modos de fazer educação, especialmente quando vírus mortais prejudicam a vida dos sujeitos sociais. A prática que realmente queremos no campo educacional é a que priorize a escuta, uma conexão de e entre todos de forma igualitária. As propostas educacionais neste período de pandemia precisam condizer com a ética e a responsabilidade, tornando-se eficientemente política.

\section{Algumas considerações}

Diante de tudo que o temos vivenciado frente ao desafio da quarentena e da própria educação online, é importante ressaltar que a conversa on line, como procedimento metodológico, em tempos de pandemia, contribuiu para que esta pesquisa pudesse ser realizada com professores de diferentes instituições de ensino nos âmbitos federal, estadual e municipal pertencentes ao Estado do Rio de Janeiro. Em relação ao uso da internet não podemos desperceber o quanto “"o capitalismo de vigilância’ vem colocando em xeque as ideias de emancipação, liberdade e conhecimento que deram origem à cibercultura" (LEMOS, 2020, p. 2). É notável também a difusão significativa das lives, seja na perspectiva do trabalho, da educação ou da diversão, concordamos que é fato que a democratização no acesso à internet não existe. Em discussão sobre a escola do futuro, não podemos ignorar que a reivindicação por escolas conectadas é uma pauta antiga (MACEDO; PRETTO; SANTOS, 2020). Os autores ressaltam que o digital está na pele da cultura e é fundante do nosso tempo, porém ainda é mais facilmente acessado por uma minoria em virtude da ausência de democratização do acesso.

Neste mesmo sentido, o uso das novas tecnologias pela escola não pode ser com o objetivo de salvar práticas antigas, mas como suportes de tessituras de conhecimentos para os nossos alunos. Os 
teóricos supracitados entendem a internet como direito humano, todos precisam ter acesso e se não houver investimento, as escolas públicas brasileiras correm risco de morte, assim como os infectados pela COVID-19.

A partir do que aqui refletimos, cabe ainda afirmar que "todo avanço tecnológico haveria de corresponder ao empenho real de resposta imediata a qualquer desafio que pusesse em risco a alegria de viver dos homens e das mulheres" (FREIRE, 1996, p. 130). Falamos aqui sobre uma questão não meramente tecnológica, mas fundamentalmente ética e política. Na quarentena do medo, luzes, câmeras e ações se voltam para a educação online, bastando saber se o discurso propagado condiz com a prática que realmente queremos.

\section{Referências}

BAKHTIN, M./VOLOCHINOV, V. N. Marxismo e Filosofia da Linguagem. 6. ed. São Paulo: Hucitec, 1992.

BRASIL, Lei 9394 de 20 de dezembro de 1996. Diretrizes e Bases da Educação Nacional. Brasília, DF: MEC, 1996. Disponível em: <https://cutt.ly/Go3376H>. Acesso em: 08 jul. 2020.

BRASIL. Ministério da Educação. Secretaria de Educação Básica. Diretrizes Curriculares Nacionais para a Educação Infantil. Brasília: MEC/SEB, 2013. Disponível em: < encurtador.com.br/ruyLT> Acesso em 08 jul. 2020.

CERTEAU, M. A invenção do cotidiano: 1. Artes de fazer/Michel de Certeau; Tradução de Ephraim Ferreira Alves. 22 ed. - Petrópolis, RJ: Vozes, 2014.

COUTO, M. Poesia é boa aliada na era da pandemia, avalia Mia Couto. Entrevista concedida a José Carlos Vieira Jornal Braziliense. Brasília, 22 abr.2020. Disponível em:

< encurtador.com.br/oQTV8 > Acesso em: 08 jul. 2020.

DUNLEY, G. A festa tecnológica: o trágico e a crítica da cultura informacional. São Paulo: Editora Escuta/Rio de Janeiro: Fiocruz, 2005.

FREIRE, P. Pedagogia da Autonomia: Saberes necessários à prática educativa. São Paulo: Paz e Terra, 1996.

GEGE, Grupo de Estudos dos Gêneros do Discurso. Palavras e Contrapalavras: Conversando sobre os trabalhos de Bakhtin. São Carlos: Pedro \& João Editores, 2010.

GOULART, C. Enunciar é argumentar: analisando um episódio de uma aula de História com base em Bakhtin. Pro-Posições, Campinas, v.18, n.3 (54) - set./dez. 2007. Disponível em:

<encurtador.com.br/ntHI9> Acesso em: 08 jul. 2020.

HENRIQUE, T. COVID-19 e a internet (ou estou em isolamento social físico). Interfaces Cientificas Humanas e Sociais, Aracaju, v. 8, n. 3, p. 173-176, 2020. Disponível em: <https://bit.ly/2KMPtG5>. Acesso em: 07 jul. 2020. 
LEMOS. A. Os desafios atuais da Cibercultura. Laboratório de Pesquisa em mídia digital, Redes e Espaço (LAB 404). Disponível em: < encurtador.com.br/fEOPZ> Acesso em 12 jun. 2020.

MACEDO, R.; PRETTO, N.; SANTOS, E. Formação de Professores, educação online e democratização do acesso às redes. UFBA. Bahia. 21 mai. 2020. (1h $31 \mathrm{~min} .56 \mathrm{~s}$.) son., color. Disponível em:

<encurtador.com.br/dhyAY> Acesso em: 08 jul. 2020.

MCLUHAN, M. Os meios de comunicação como extensões do homem. Tradução de Décio Pignatare. São Paulo: Cultrix, 2007.

OLIVEIRA, A. P. S. C. O Curso Normal entre Mídias e Novas Tecnologias: Um Olhar Atento sobre as Políticas em Texto. In. VII Seminário Vozes da Educação - Resistências, políticas e poéticas na vida e na educação: Regina Leite Garcia, presente! TAVARES, Maria Tereza Goudart, ARAUJO, Mairce da Silva, OLIVEIRA, Daniel de org. - 1 ed. - São Gonçalo, RJ: UERJ, Faculdade de Formação de Professores, 2019. 2000 p.:pdf.

. Tecnologias de Reação no Tempo da Cibercultura: Astúcias dos Normalistas em Relação às Mídias na Escola. In. VII Seminário Vozes da Educação - Resistências, políticas e poéticas na vida e na educação: Regina Leite Garcia, presente! TAVARES, Maria Tereza Goudart, ARAUJO, Mairce da Silva, OLIVEIRA, Daniel de org. - 1 ed. - São Gonçalo, RJ: UERJ, Faculdade de Formação de Professores, 2019. 2000 p.:pdf.

. Práticas Formativas no contexto da cibercultura: desafios e possibilidades em uma disciplina do Curso Normal. 2017. 170f. Dissertação (Mestrado em Educação: Processos Formativos e Desigualdades Sociais). Faculdade de Formação de Professores, Universidade do Estado do Rio de Janeiro, São Gonçalo, 2017.

RIO DE JANEIRO (Estado) Secretaria de Estado de Educação - SEEDUC. Educação: Planejamento Escolar. Texto com orientações sobre o Currículo Mínimo.2013. Disponível em:

$<$ https://cutt.ly/uo8onQw>. Acesso em: 08 jul. 2020.

SANTOS, B. S. Para uma sociologia das ausências e uma sociologia das emergências. In. Revista Crítica de Ciências Sociais, 63, 2002, p. 237-280.

. A Cruel Pedagogia do Vírus: Edições Almedina, S.A. Coimbra, 2020.

SANTOS. E. Diário online: Dispositivo Multirreferencial de pesquisa formação na cibercultura. $1^{\mathrm{a}}$ edição, Santo Tirso, 2014: Portugal. Whitebooks.

SERPA, A. Conversas: Caminhos da Pesquisa com o Cotidiano. A página da educação edição n.189, série II. Disponível em:< https://bit.ly/2AJBmjG> Acesso em: 08 jul. 2020 .

SIBILIA, P. Redes ou paredes: a escola em tempos de dispersão. Tradução Vera Ribeiro. Rio de Janeiro: Contraponto, 2012.

SILVA, M. Sala de Aula Interativa: educação, comunicação, mídia clássica.7 edição. São Paulo: Edições Loyola, 2014. 

análise do Plano de Desenvolvimento da Educação e das Metas do novo Plano Nacional de Educação. In. Revista Ibero-Americana de Estudos em Educação, v. 10, n. 4, out./dez. (2015).

\footnotetext{
${ }^{i}$ Doutoranda no Programa de Pós-graduação em Educação (ProPEd) da Universidade do Estado do Rio de Janeiro e membro do grupo de pesquisas Infância, Juventude, Educação e Cultura (IJEC). Professora de Educação Infantil do Colégio Pedro II.
} Rio de Janeiro, Brasil. E-mail: adrielesfoliveira@gmail.com / Orcid: https://orcid.org/0000-0001-6513-4630

${ }^{i i}$ Doutoranda no Programa de Pós-graduação em Educação (ProPEd) da Universidade do Estado do Rio de Janeiro e membro do grupo de pesquisas Infância, Juventude, Educação e Cultura (IJEC). Professora dos Anos Iniciais do Ensino Fundamental na Prefeitura de Niterói/RJ e orientadora educacional na Prefeitura de São Gonçalo. Rio de Janeiro, Brasil. E-mail: Alessandra.uerj2005@gmail.com / Orcid: https://orcid.org/0000-0002-1266-1354

iii Doutoranda no Programa de Pós-graduação em Educação (ProPEd) da Universidade do Estado do Rio de Janeiro e membro do grupo de pesquisas Infância, Juventude, Educação e Cultura (IJEC). Professora das disciplinas pedagógicas da rede pública de ensino do Estado do Rio de Janeiro e orientadora pedagógica na Prefeitura de Araruama. Rio de Janeiro, Brasil. E-mail: Ana.pedagogia@yahoo.com.br / Orcid: https://orcid.org/0000-0003-0135-951X

${ }^{\text {iv }}$ Números atualizados diariamente no site da UNESCO. Disponível em: <https://pt.unesco.org/covid19/Educationresponse>. Acesso em 11 jun. 2020.

` Aplicativo com conteúdo pedagógico para alunos estudarem em casa já teve 260 mil acessos. Matéria publicada em 23 de mar 2020. Disponível em: < encurtador.com.br/uFGJY>. Acesso em 11 jun. 2020.

vi Nota à comunidade - Ensino a distância. Publicada no dia 18 de março de 2020. Disponível em: < encurtador.com.br/cAGLR >. Acesso em: 11 jun. 2020.

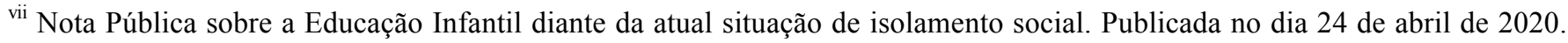
Disponível em: < encurtador.com.br/entF0> Acesso em: 11 jun. 2020.

viii Manifesto da ANPEd. Educação a distância na Educação Infantil, não! Publicado em 20 abr 2020. Disponível em: < encurtador.com.br/bqB49 > Acesso em 15 jun 2020.

${ }^{\text {ix }}$ Denominamos de plataforma oficiosa as redes sociais utilizadas no cotidiano dos estudantes e professores onde adaptamos nossos ambientes virtuais de aprendizagem (AVA) devido à ausência de uma plataforma específica para a educação nas escolas públicas, especialmente as Estaduais. Justificamos a expressão "oficiosa" porque o facebook e whatsApp não são plataformas específicas para práticas de ensino e aprendizagem. Rompemos com uma lógica do consumo pensada por seus fabricantes e como usuários reprogramamos seus usos (CERTEAU, 2014).

${ }^{\mathrm{x}}$ Expressão utilizada com freqüência após momentos de crise como o do Coronavírus fazendo relação ao retorno à vida sob um normal diferente daquele anterior ao período da pandemia, exigindo da sociedade outros modos de portar-se.

${ }^{x i}$ Uma plataforma do Google destinada a realizar chamadas de videoconferência em computadores e dispositivos móveis. Mais informações em: https://www.qinetwork.com.br/google-meet-entenda-como-funciona/ Acesso em: 10 jun.2020.

${ }^{\text {xii }}$ Disponível em: $<$ https://edu.google.com/products/classroom/?modal_active=none $>$. Acesso em 15 jun. 2020.

xiii Disponível em: <encurtador.com.br/abtDE>. Acesso em: 14 jun. 2020.

${ }^{\text {xiv }}$ Disponível em: <encurtador.com.br/eqxDP > . Acesso em: 14 jun. 2020. 